\title{
Periodontal disease may associate with breast cancer
}

\author{
Birgitta Söder, Maha Yakob, Jukka H. Meurman, Leif C. Andersson, Björn Klinge, \\ Per-Östen Söder
}

B. Söder, M.Yakob, B. Klinge, P-Ö. Söder

Department of Dental Medicine, Division of Periodontology, Karolinska Institutet, Box 4064, Huddinge, Sweden

J.H. Meurman

Institute of Dentistry and Department of Oral and Maxillofacial Diseases, Helsinki University Central Hospital, Helsinki, Finland

L.C. Anderssson

Department of Pathology, Haartman Institute, University of Helsinki, Helsinki, Finland

Running title: Dental infections and breast cancer

Key words: Breast cancer; Periodontitis; Missing molar teeth,

Address for correspondence:

Dr Birgitta Söder

Department of Dental Medicine

Division of Periodontology

Karolinska Institutet

Box 4064

14104 Huddinge, Sweden

Tel: +4685248 8241

Fax +4686638306

E-mail:birgitta.soder@ki.se 


\begin{abstract}
Purpose The main purpose was to evaluate the association between periodontal disease and the incidence of breast cancer in a prospective study of 3273 randomly-selected subjects aged 30-40 years at baseline.
\end{abstract}

Methods Breast cancer incidence was registered from 1985 to 2001 according to the WHO International Classification of Diseases criteria. At baseline, 1676 individuals also underwent a clinical oral examination (Group A) whereas 1597 subjects were not clinically examined but were registered (Group B). The associations between breast cancer, periodontal disease and missing molars were determined using multiple logistic regression models with several background variables and known risk factors for cancer.

Results In total 26 subjects in group A and 15 subjects in group B had breast cancer. The incidence of breast cancer was $1.75 \%$ in subjects who had periodontal disease and/or any missing molars, and 0 in subjects who had periodontal disease but had no missing molars. For periodontally healthy subjects with no missing teeth the breast cancer incidence was $1 \%$. For Group B the respective incidence was $0.94 \%$. Female gender (odds ratio [OR] 13.08) and missing any molar in the mandible (OR 2.36) were explanatory variables for breast cancer. Of the subjects with periodontal disease and any missing molars in the mandible $5.5 \%$ had breast cancer in comparison to $0.5 \%$ of the subjects who had periodontal disease but no missing molars in the mandible $(\mathrm{p}<0.02)$.

Conclusions Chronic periodontal disease indicated by missing molars seemed to associate statistically with breast cancer. 


\section{Introduction}

Inflammation is a key feature in many chronic diseases including cancer [1-2]. Inflammation caused by infections seems to be one of the most important preventable causes of cancer in humans [3]. Periodontal disease is characterized by chronic infection and inflammation leading to destruction of the bone surrounding the teeth. The disease may take decades to develop and it ultimately leads to tooth loss [4-5]. An estimated 15-35\% of the adult population in industrialized countries suffers from this multifactor disease [6-8]. Periodontal disease involves complex interactions of host defence, bacteria, and virus. Periodontal disease is initiated by a biofilm of bacteria on the teeth which triggers an immune-inflammatory response in the adjacent host tissues $[4,9]$. Numerous oral bacterial species have been associated with periodontal disease [10-11] . Human cytomegalovirus (HCMV), Epstein-Barr virus (EBV) and HCMV-EBV co-infection seems to be closely associated with disease-active periodontitis. [12-14] . Infection by HCMV or EBV seems to inhibit the macrophages to respond to bacterial challenge, and thus have pathogenic role in the development of periodontal disease. [15] The associations between infectious agents of putative bacterial pathogens, herpes viruses, Epstein-Barr virus (EBV) type 1, cytomegalovirus (CMV) seems to play an important synergistic role in the pathogenesis of chronic periodontitis. [16-18] .

Breast cancer is the most common malignancy in women worldwide and it is the leading cause of cancer-related mortality [19]. Incidence rates are high in developed countries and are also increasing in the developing world [20]. National income and health expenditures are known to affect breast cancer incidence but these factors only partly explain variations in mortality rates [20]. Viral infections such as human papilloma virus infections seem to associate with breast cancer as shown in a recent meta-analysis [21] In general, persistent and prevalent infections in populations appear to link with malignancies [22]. In Sweden breast cancer represents $29 \%$ of all cancers in the female [23]. Breast cancer also has a hereditary component [24].

The results of an epidemiological study 2001, from our group, showed that fairly young individuals with periodontal disease and missing molars are at increased risk of premature 
death caused by life threatening diseases such as malignant neoplasm, cardiovascular diseases, and diseases of the digestive system [25]. Recently, periodontal disease was also found to associate with head and neck cancer in patients who never smoked or consumed alcohol [26]. Poor oral health has been statistically associated with the prevalence of many types of cancer such as pancreatic and gastrointestinal cancer [27]. Consequently, the hypothesis for the present study was that a low degree chronic inflammation such as seen in periodontal disease is involved in carcinogenesis.

For that reason the specific aim of the present investigation was to study the incidence of breast cancer from 2001 in subjects with periodontal disease and characteristic tooth loss in our 16-year prospective investigation.

\section{Materials and Methods}

\section{Study population}

In 1985 we undertook this longitudinal prospective study, which comprised a random sample cohort of 3273 individuals aged 30-40 years. The subjects were selected from a registry database of all inhabitants $(n=105,798)$ of Stockholm County born on the 20th of any month from 1945 to 1954 inclusive. They were informed about the purpose of the study and offered a clinical oral examination. In total, 1676 individuals (51.2\%; 838 men and 838 women) underwent a detailed clinical oral examination (Group A). The remaining 1597 subjects (849 men and 748 women) did not have the clinical examination and constituted Group B. Figure 1 shows the study profile.

\section{Clinical examination}

For all subjects of the clinically examined Group A the following parameters were recorded: the number of remaining teeth excluding third molars; gingival inflammation around every tooth as assessed using the gingival index [28]; and oral hygiene status as determined by using both the dental plaque [29] and the calculus indices to assess all six surfaces of six representative teeth. Pocket depth was determined using a periodontal probe and recorded to the nearest higher millimetre for six sites of each tooth. Presence or absence of each tooth was recorded. The prevalence of periodontal disease was determined in each age group year by year from 31 years of the age to 40. All subjects in Group A also filled in a structured 
questionnaire containing questions about factors such as regular dental visits and the use of tobacco. Smoking was divided into smokers and former smoker categories. The smokers reported the number of cigarettes per day, and the number of years of smoking. Former smokers reported when they had quit smoking and also the number of cigarettes per day and years of smoking. Smoking was then further analyzed as pack-years. The Ethics Committee of the Karolinska Institute and Huddinge University Hospital, Sweden, approved the study protocol. The study is in accordance with the Declaration of Helsinki.

\section{Cancer and socio economic data}

The data for cancer (malignant neoplasm) and causes of death were obtained from the Centre of Epidemiology, Swedish National Board of Health and Welfare, Sweden. The data were classified according to the WHO International Statistical Classification of Diseases and Related Health Problems ICD-7, ICD-9 and ICD-10. Socio-economic data were obtained from the National Statistics Centre, Örebro, Sweden.

\section{Statistical analyses}

Analysis of variance, chi-square test, Fisher's exact t-test and multiple logistic regression analyses were applied when appropriate. Multiple logistic regression analysis was used to compare the incidence of cancer, according to the state of oral health at baseline, while simultaneously controlling for confounding variables. The confounding variables included age, gender, education, income, socioeconomic status, smoking habits, and dental visits. Smoking habits were dichotomized into the number of smokers (ever smokers) and the number of never smokers. The model with the confounders was correlated to the incidences of cancer. A backwards elimination method was used to control for multicollinearity (correlation between confounders). The statistical model was tested according to Cox \& Snell [30] and Nagelkerke [31].

\section{Results}

In the total cohort of 3273 subjects, 41 subjects (1.3\%) were diagnosed as having breast cancer; comprising 39 women and 2 men. Breast cancer had been diagnosed at the mean age of $45.8 \pm 6.8$. In the clinically examined Group A comprising 1676 subjects, 26 persons (1.6\%) had breast cancer; 24 women and two men; whereas in Group B with 1597 subjects, 15 women $(0.9 \%)$ had breast cancer. 
The prevalence of periodontal disease in Group A significantly increased year by year, in women from $9.8 \%$ at the age of 31 to $25.6 \%$ at the age of $40(\mathrm{p}<0.001)$ and in men from $8.5 \%$ at the age of 31 to $35.0 \%$ at the age of 40 ( $p<0.001)$. In total $17.1 \%$ had periodontal disease diagnosed at the 1985 baseline examination.

Of the subjects with breast cancer 12 subjects were smokers (42.8\%); 5 were former smokers (17.9\%), whereas 11 had never smoked (39.3\%). Of the remaining 1648 subjects with no breast cancer 605 were smokers (37.7\%), 432 were former smokers (26.2\%), and 611 had never smoked (37.1\%). For the subjects with breast cancer, a mean of $2411.3 \pm 2811.4$ S.D. pack-years of smoking was calculated; for those with no breast cancer the respective packyears were $3643.0 \pm 5195.7$ S.D. The difference between the groups was statistically not significant (NS).

The demographic and oral health data at baseline in 1985 for subjects with and without periodontal disease are shown in Table 1. The demographic data and oral health data in 1985 for subjects with or without breast cancer in 2001 are shown in Table 2. In the multiple logistic regression model with breast cancer as the dependent variable, female gender appeared to be the principal independent predictor associated with 13.08-fold the risk for breast cancer. Those subjects with any missing molar had 2.36-fold the risk for breast cancer. The results are given in Table 3. The incidence figures for breast cancer for the clinically examined Group A showed that $1.75 \%$ of those with any missing molar had breast cancer whereas only $0 \%$ of the subjects with no missing molar had cancer (Table 4 ). The difference in the prevalence of breast cancer for subjects with periodontal disease and with or without any missing molar in the mandible was significant $(\mathrm{p}<0.02)$, see Table 5.

\section{Discussion}

This study addressed the issue of chronic dental infections, and periodontal disease in particular, as a risk factor for breast cancer. Our results clearly identified periodontal disease and loss of any molar from the mandible as an independent predictor for breast cancer. Consequently, our study hypothesis based on the paradigm of chronic infection/inflammation vs. breast cancer was confirmed. 
Some comments should be made concerning the reliability of the results. Our subjects were randomly chosen to avoid selection bias. The large subject pool was representative of the ethnically homogenous Swedish adult population, with an age range of 10 years to limit the influence of age differences. The study had a longitudinal prospective design with a cohort of subjects of whom many had periodontal disease documented at baseline 16 years earlier. The participants were born on the $20^{\text {th }}$ of any month between 1945 and 1954 and therefore it was possible to get the diagnosis of breast cancer for each participant up to the year 2001 from the National Cancer Registry Centre of Epidemiology, Swedish National Board of Health and Welfare. This registry collects cancer data from all subjects in Sweden born on the $20^{\text {th }}$ of any month.

Further comments should be made about the missing molars which in this study were used as a proxy for chronic dental infections. The first permanent teeth to erupt are the first and second permanent molars [32]. The newly erupted molars can be infected by oral bacteria from the primary dentition or by intra-familial transmission [33-34]. Our study subjects who had lost their molars already by 1985 had most probably been suffering from periodontal disease for many years. Namely, the reason for molar tooth extraction is either due to dental caries or periodontal disease. The reason could not be identified in our data. However, dental caries is also a chronic infectious disease leading to pulp infections and periapical abscesses with subsequent systemic spread of micro-organisms. Thus the end result of both periodontal disease and caries is a systemic infection burden and often leading to tooth extraction. Hence we felt justified to use missing molars as a proxy for long-lasting dental infections in our analyses.

The inevitable increase of periodontal disease with age poses a threat to large patient groups who then will be exposed to chronic infections with systemic consequences. Hence, periodontal disease may indeed contribute to the increasing incidence of breast cancer in middle aged and older people. The development of cancer obviously depends on differences in the characteristic carcinogenesis and thus the impact of the role infection and inflammation depends on the etiopathogenesis of the neoplasm in question.

Our findings may nevertheless have importance in the ongoing discussion about life style and the risk of cancer. The results also have public health consequences. There is a well warranted basis for prophylactic measures against the prevalence and outcome of periodontal disease in 
addition to the costs it incurs to societies. Even if periodontal disease is only one contributor to the carcinogenic process a strategy to remove this burden might reduce the incidence of breast cancer worldwide.

\section{Conclusions}

This is to our knowledge the first study presenting data about the eventual risk that longstanding dental infections may present risk for breast cancer. Chronic periodontal disease indicated by missing molars seemed to associate statistically with breast cancer. If our results will be confirmed in future studies the finding should have clinical consequences in advising the patients.

Acknowledgements The Swedish Heart-Lung Foundation, the AFA Insurance, Sweden, Philips Oral Health Care, Sweden and the Karolinska Institutet, Stockholm, Sweden, and by grant TI020Y0003 from the Helsinki University Central Hospital, Finland. Grant from The Medical Society of Finland. 


\section{References}

1. Coussens LM, Werb Z: Inflammation and cancer. Nature 2002, 420(6917):860-867.

2. Mantovani A, Allavena P, Sica A, Balkwill F: Cancer-related inflammation. Nature 2008, 454(7203):436-444.

3. Kuper H, Adami HO, Trichopoulos D: Infections as a major preventable cause of human cancer. J Intern Med 2000, 248(3):171-183.

4. Page RC, Offenbacher S, Schroeder HE, Seymour GJ, Kornman KS: Advances in the pathogenesis of periodontitis: summary of developments, clinical implications and future directions. Periodontol 2000 1997, 14:216-248.

5. Pihlstrom BL, Michalowicz BS, Johnson NW: Periodontal diseases. Lancet 2005, 366(9499):1809-1820.

6. Albandar JM: Periodontal diseases in North America. Periodontol 20002002 , 29:31-69.

7. Gjermo P, Rosing CK, Susin C, Oppermann R: Periodontal diseases in Central and South America. Periodontol 2000 2002, 29:70-78.

8. Sheiham A, Netuveli GS: Periodontal diseases in Europe. Periodontol 2000 2002, 29:104-121.

9. Socransky SS, Haffajee AD: Dental biofilms: difficult therapeutic targets. Periodontol 2000 2002, 28:12-55.

10. Haffajee AD, Socransky SS: Microbiology of periodontal diseases: introduction. Periodontol 2000 2005, 38:9-12.

11. Socransky SS, Haffajee AD: Periodontal microbial ecology. Periodontol 2000 2005, 38:135-187.

12. Grenier G, Gagnon G, Grenier D: Detection of herpetic viruses in gingival crevicular fluid of patients suffering from periodontal diseases: prevalence and effect of treatment. Oral Microbiol Immunol 2009, 24(6):506-509.

13. Slots J: Update on human cytomegalovirus in destructive periodontal disease. Oral Microbiol Immunol 2004, 19(4):217-223.

14. Slots $\mathrm{J}$ : Herpesviruses, the missing link between gingivitis and periodontitis? $J$ Int Acad Periodontol 2004, 6(4):113-119.

15. Lin YL, Li M: Human cytomegalovirus and Epstein-Barr virus inhibit oral bacteria-induced macrophage activation and phagocytosis. Oral Microbiol Immunol 2009, 24(3):243-248.

16. Botero JE, Parra B, Jaramillo A, Contreras A: Subgingival Human Cytomegalovirus Correlates With Increased Clinical Periodontal Parameters and Bacterial Coinfection in Periodontitis. J Periodontol 2007, 78(12):2303-2310.

17. Chalabi M, Rezaie F, Moghim S, Mogharehabed A, Rezaei M, Mehraban B: Periodontopathic bacteria and herpesviruses in chronic periodontitis. Mol Oral Microbiol 2010, 25(3):236-240.

18. Saygun I, Kubar A, Sahin S, Sener K, Slots J: Quantitative analysis of association between herpesviruses and bacterial pathogens in periodontitis. $J$ Periodontal Res 2008, 43(3):352-359.

19. Murray CJ, Lopez AD: Mortality by cause for eight regions of the world: Global Burden of Disease Study. Lancet 1997, 349(9061):1269-1276. 
20. Igene H: Global health inequalities and breast cancer: an impending public health problem for developing countries. Breast $J$ 2008, 14(5):428-434.

21. Li N, Bi X, Zhang Y, Zhao P, Zheng T, Dai M: Human papillomavirus infection and sporadic breast carcinoma risk: a meta-analysis. Breast Cancer Res Treat 2010.

22. Glaser SL, Hsu JL, Gulley ML: Epstein-Barr virus and breast cancer: state of the evidence for viral carcinogenesis. Cancer Epidemiol Biomarkers Prev 2004, 13(5):688-697.

23. Boström G, Persson G: The development and Distribution of Public Health. Sand J Public Health 2001, Suppl 58:17-36.

24. Trichopoulos D, Adami HO, Ekbom A, Hsieh CC, Lagiou P: Early life events and conditions and breast cancer risk: from epidemiology to etiology. Int J Cancer 2008, 122(3):481-485.

25. Soder B, Jin LJ, Klinge B, Soder PO: Periodontitis and premature death: a 16-year longitudinal study in a Swedish urban population. J Periodontal Res 2007, 42(4):361-366.

26. Tezal M, Sullivan MA, Hyland A, Marshall JR, Stoler D, Reid ME, Loree TR, Rigual NR, Merzianu M, Hauck L et al: Chronic periodontitis and the incidence of head and neck squamous cell carcinoma. Cancer Epidemiol Biomarkers Prev 2009, 18(9):2406-2412.

27. Meurman JH: Oral microbiota and cancer. J Oral Microbiol 2010, 2:5195.

28. Silness J, Loee H: Periodontal Disease In Pregnancy. Ii. Correlation Between Oral Hygiene And Periodontal Condtion. Acta Odontol Scand 1964, 22:121-135.

29. Löe H, Silness J: Periodontal Disease In Pregnancy. I. Prevalence And Severity. . Acta Odontol Scand, 1963, 21:533-551.

30. Cox DR, Snell EJ: On test statistics calculated from residuals. Biometrica 1971, 58(3):589-594.

31. Nagelkerke NJD: A note on a general definition of the cefficient of determination. Biometrica 1991, 78(3):691-692.

32. Ekstrand KR, Christiansen J, Christiansen ME: Time and duration of eruption of first and second permanent molars: a longitudinal investigation. Community Dent Oral Epidemiol 2003, 31(5):344-350.

33. Kulekci G, Leblebicioglu B, Keskin F, Ciftci S, Badur S: Salivary detection of periodontopathic bacteria in periodontally healthy children. Anaerobe 2007.

34. Umeda M, Miwa Z, Takeuchi Y, Ishizuka M, Huang Y, Noguchi K, Tanaka M, Takagi Y, Ishikawa I: The distribution of periodontopathic bacteria among Japanese children and their parents. J Periodontal Res 2004, 39(6):398-404. 
Fig. 1 Study profile

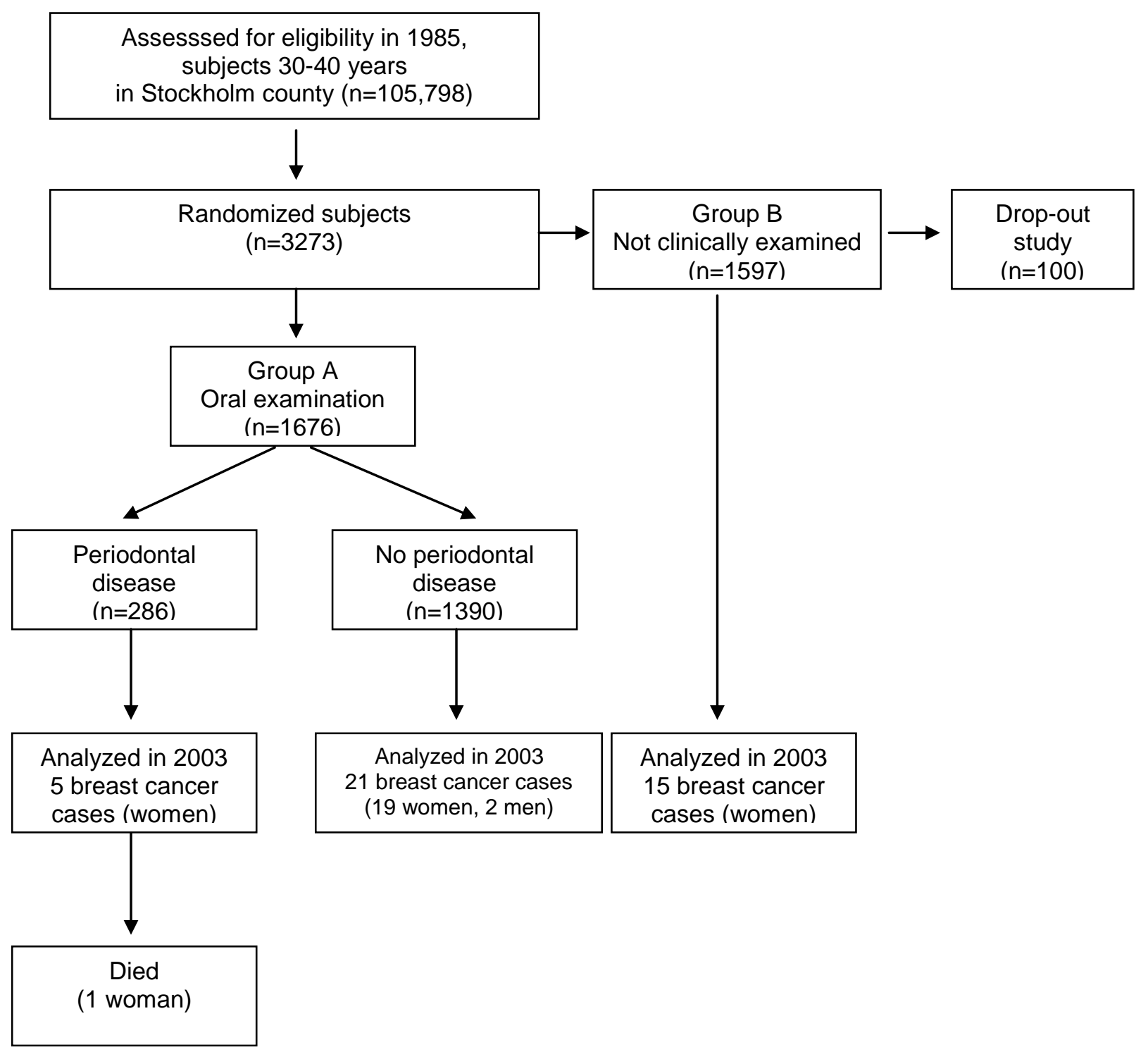


Table 1 Demographic clinical oral health data of subjects of Group A with or without diagnosed periodontal disease at the baseline examination in 1985.

No periodontal disease $\quad$ Periodontal disease $\quad p^{*}$

$$
(\mathrm{n}=1390) \quad(\mathrm{n}=286)
$$

number, mean $\pm \mathrm{SD} \quad$ number, mean $\pm \mathrm{SD}$

Gender (female/male)

Age in 1985 (years)

Education (compulsory/higher)

Smoking (pack-year)

Income (Swedish Crowns x 1000)

Plaque index ${ }^{[28]}$

Gingival inflammation ${ }^{[29]}$

Calculus index

Missing teeth

Missing molars in the mandible

$$
159 / 825
$$

$35.6 \pm 2.8$

$218 / 1172$

$3315.5 \pm 5041.2$

$188.5 \pm 102.9$

$0.67 \pm 0.47$

$1.18 \pm 0.47$

$0.39 \pm 0.54$

$1.19 \pm 2.37$

$0.30 \pm 0.74$
$127 / 851$

$<0.05$

$36.5 \pm 2.8$

$73 / 286$

$<0.001$

$5060.5 \pm 5455.7$

$<0.001$

NS

$186.4 \pm 89.3$

$<0.001$

$0.99 \pm 0.53$

$<0.001$

$1.76 \pm 0.54$

$<0.001$

$1.59 \pm 2.40$

$=0.01$

$0.44 \pm 0.89$

$<0.01$

\footnotetext{
* Fisher's exact t/test or Student's t-test for unpaired samples as appropriate. Data are expressed as mean \pm SD.
} 
Table 2 Demographic and clinical oral data for subjects with periodontitis 1985, with and without breast cancer 2001

$\begin{array}{cc}\text { Periodontitis } 1985 & \text { Periodontitis } 1985 \quad p^{*} \\ \text { without } & \text { with }\end{array}$

breast cancer $2001 \quad$ breast cancer 2001

$$
(\mathrm{n}=281) \quad(\mathrm{n}=5)
$$

number, mean $\pm \mathrm{SD}$ number, mean $\pm \mathrm{SD}$

Gender (male/female)

Age in 1985 (years)

Education (compulsory/higher)

Smoking (pack-year)

$5107.1 \pm 5482.6$

$2445.5 \pm 2814.3$

NS

Income (Swedish Crowns x 1000)

$178.7 \pm 92.2$

$150.2 \pm 53.0$

NS

Plaque index ${ }^{[28]}$

$0.90 \pm 0.537$

$0.87 \pm 0.61$

NS

Gingival inflammation ${ }^{[29]}$

$1.76 \pm 0.54$

$2.12 \pm 0.45$

NS

Calculus index

$0.80 \pm 0.72$

$0.97 \pm 0.62$

NS

Number of deep pockets $(>5 \mathrm{~mm})$

Number of remaining teeth

$5.1 \pm 5.1$

$8.6 \pm 3.0$

NS

Number of missing molars

$26.5 \pm 2.3$

$0.7 \pm 1.4$

$23.6 \pm 5.6$

$<0.01$

Number of missing molars

in the mandible

$0.4 \pm 0.9$

$1.6 \pm 1.5$

$=0.003$

Number of missing front teeth
$0.7 \pm 1.4$

$2.4 \pm 2.6$ 
Table 3 Results of the multiple logistic regression analysis. Breast cancer was the dependent variable and age, gender, education level, socio economic status, working history, yearly income, smoking in pack-years, dental appointments, dental plaque index, gingival bleeding index, and loss of any molar tooth in the mandible were used as explanatory variables.

\begin{tabular}{|c|c|c|c|c|c|c|}
\hline $\begin{array}{c}\text { Dependent } \\
\text { variable }\end{array}$ & Explaining variable & B & $X^{2}$ & $p$ & $\begin{array}{l}\text { Odds } \\
\text { ratio } \\
\end{array}$ & $\begin{array}{c}95 \% \text { confidence } \\
\text { interval } \\
\end{array}$ \\
\hline & Gender (female) & 2.57 & 12.21 & $<0.001$ & 13.08 & $3.09-55.32$ \\
\hline Breast cancer & $\begin{array}{l}\text { Missing any molar from the } \\
\text { mandible }\end{array}$ & 0.86 & 4.55 & 0.033 & 2.36 & $1.07-5.21$ \\
\hline
\end{tabular}

Cox \& Snell $\mathrm{R}^{2}=0.017 ;$ Nagelkerke $\mathrm{R}^{2}=0.11$ 
Table 4 Percentage of breast cancer $2001^{\dagger}$ for subjects in A with periodontitis and periodontitis with missing any molar as well as subjects with no periodontitis and no missing teeth and subjects in B.

A

$$
(n=1676)
$$

Breast cancer

$(n=26)$
B

$(n=1597)$

Breast Cancer

$(\mathrm{n}=15)$

\section{Periodontitis}

$$
(n=286)
$$

Periodontitis

Periodontitis

No periodontitis

and

$(\mathrm{n}=96)$

$(\mathrm{n}=1390)$

missing any molar

$$
(n=190)
$$

Breast cancer

Breast cancer

Breast cancer

Breast cancer

$(\mathrm{n}=5)$

$(n=0)$

$(\mathrm{n}=21)$

$(\mathrm{n}=15)$

0

$1.51 \%$

$0.94 \%$

Group A was clinically orally examined whereas Group B data refer register information only.

${ }^{\dagger}$ According to International Classification of Diseases, ICD-8, ICD-9 in1985-1996 and ICD10 in $1997-2000$. 
Table 5 Percentage of breast cancer in subjects with periodontal disease with or without any missing molar teeth.

Missing molars in the mandible No missing molars in the mandible $\quad p$

$(n=73)$

$(n=213)$

$\begin{array}{llll}\text { Percent } & 5.48 & 0.47 & <0.02\end{array}$


